\title{
Pintura presente. Uma breve incursão nos desenhos de Roland Barthes.
}

\author{
Juliana Bratfisch ${ }^{1}$ \\ para Rodrigo Fontanari
}

RESUMO: 0 nanquim, o guache, a aquarela: o traço fluído de Barthes é uma tentativa de captar um instante efêmero, a inscrição dos signos flutuantes de cada manhã de domingo em que ele fazia os seus "borrões", como ele próprio diz; é certamente um instante de significância daquele que traça e colore, mas também é um dom: Barthes inscreve seu corpo em um frágil suporte - muitas vezes em um papel de pouca gramatura destinado à escrita, como são as folhas timbradas da École de Hautes Études - não para se afirmar como artista, mas pelo simples prazer de dedicar esse gesto amador a seus amigos, presenteando-os com seu resultado. 0 gesto pictural em Barthes acontece, portanto, também sob o signo da anacoluthia, "o campo raro em que as ideias se penetram de afetividade, em que os amigos, pelo cortejo com que acompanham nossa vida, permitem-nos pensar, escrever, falar" ("A Imagem" o rumor da língua, p. 444). Nessa comunicação farei uma análise do gesto pictural em Barthes não somente como um gesto produtor, olhando para os signos que hesitam prazerosamente entre a letra e a imagem, mas também como um gesto de oferta.

PALAVRAS-CHAVE: Pintura; Roland Barthes; Traço; Presente; Escrita; Anacoluthia.

\section{A presentpainting. A brief incursion in Roland Barthes' drawings.}

ABSTRACT: Indian ink, gouache, watercolour: Barthes' fluid trace is an attempt to capture the vanishng instant, the floating inscription signs of every Sunday morning in which he used to produce his ink blots, as he says himself.It certainly is an instant of significance for him who traces and paints, but at the same time it is a gift: Barthes inscribes his body in a fragile material - usually a very thin sheet of paper as those letterheads from the École des Hautes Études - not in order to afirm himself as an artist, but for the simple pleasure of dedicating this amateur gesture to his friends, presenting them with his production. The pictorial gesture in Barthes happens, therefore, as a sign of anacoluthia, i.e. the rare space in which our ideas penetrate each other with afect, in which friends, by walking by our side and by sharing our path, allow us to think, write, speak. In this paper I analyse the pictorial gesture in Roland Barthes not only as producing gesture, regarding the signs that delightedly vacilate between letter and image, but essencially as an offering one.

KEYWORDS: Painting; Roland Barthes; Trace; Present; Writing; Anacoluthia.

A partir de 1971 a pintura se faz presente na vida de Roland Barthes. Apesar de menos expressiva dentro do interesse geral que se desenvolveu por sua obra - mais conhecida por seu trabalho como semiólogo, crítico literário ou mesmo escritor -, a pintura é uma produção que não deveria ser menosprezada dentro do conjunto de sua obra. É verdade que para o leitor brasileiro, familiarizado com as várias reproduções nas capas das traduções publicadas pela editora Martins Fontes, tal menosprezo talvez possa ser nuançado senão pelo escasso estudo - tão escasso quanto na França ou qualquer parte do mundo -, ao menos pela insistente convivência. Entretanto, é preciso muito mais do que insistência e reprodução para dizer que a produção gráfica de Barthes não deveria ser menosprezada. Em um vídeo produzido pelo Institut national du Patrimoine e pela revista Connaissance des Arts, Guillaume Fau, um dos responsáveis pelo Fonds Roland Barthes na BnF,contabiliza 385 desenhos catalogados, afirmando também que esse número não chega nem perto de ser a totalidade dos desenhos produzidos por Barthes ao longo de sua vida. Estima-se uma média de 700 desenhos, em grande parte conservados em coleções privadas, o que me parece um número a ser considerado nessa reavaliação. A pintura está presente assiduamente em sua rotina, principalmente no que concerne aos anos de 1971 a 1975, coincidindo com a abertura

\footnotetext{
${ }^{1}$ Doutoranda em Teoria e História Literária pela Unicamp. Mestre em Literatura Francesa pela Universidade de São Paulo (2012-2014) com a dissertação Política do Intervalo (La voie en Roland Barthes). E-mail para contato: julianabratfisch@gmail.com.
} 
que há em sua escrita para o prazer e para o íntimo. Enquanto professor, primeiro na École de Hautes Études e posteriormente no Collège de France, sabe-se que Barthes tem uma rotina de trabalho bem regular: durante as manhãs (e também as tardes,quando não tem seminário) ele trabalha, reservando as noites para encontrar os amigos. Entretanto, em algumas manhãs, antes de passar a sua grande mesa de trabalho, ele se instala diante de uma mesa muito menor, envolta por tintas e pinceis de todos os tipos. É ali que ele traça, ele colore, ele desenha, ele rabisca - como ele mesmo diz- ou, como prefiro dizer, ele imprime seus traços, inscreve seu corpo em um frágil suporte, muitas vezes um papel de pouca gramatura destinado à escrita - como são as folhas timbradas da École de Hautes Études e do Collège de France. Antes de dar início a sua rotina de trabalho e pouco depois de acordar ele cria um intervalo para que os signos ainda possam fluir livremente, para que o sentido não se prenda imediatamente na trama inevitável da linguagem.

0 amadorismo de sua prática e a consequente impossibilidade de associar sua produção às rupturas que marcam a evolução da história da arte é o principal motivo desse desvalor. Se levarmos em conta a diversidade de técnicas e suportes utilizados por Barthes percebemos que realmente não há uma grande diversidade e quase nenhuma evolução estilística no que concerne às técnicas de traço ou de coloração. Alguns poucos desenhos seus são figurativos, como é o caso da flor datada de 29 de junho de 1971 (figura 1), cujos escritos marginais nos mostram uma produção insatisfatória devido ao desejo de "mais audácia", de "fazer grandes massas, sem procurar figurar". A maioria dos seus trabalhos, entretanto, são abstratos: linhas curvas ou manchas, sejam elas de maior dimensão ou de menor dimensão, mais próximas de uma espécie de tachismo;cores combinadas de diversas maneiras,apresentando o uso de guache, lápis, pastel ou nanquim e tendo como suporte um papel A4, seja um papel de pouca gramatura destinado à escrita ou um papel cartão. Em geral, sua pintura se limita ao quadro retangular da folha A4 na horizontal ou na vertical, sendo raras aquelas que possuem uma forma mais circular.

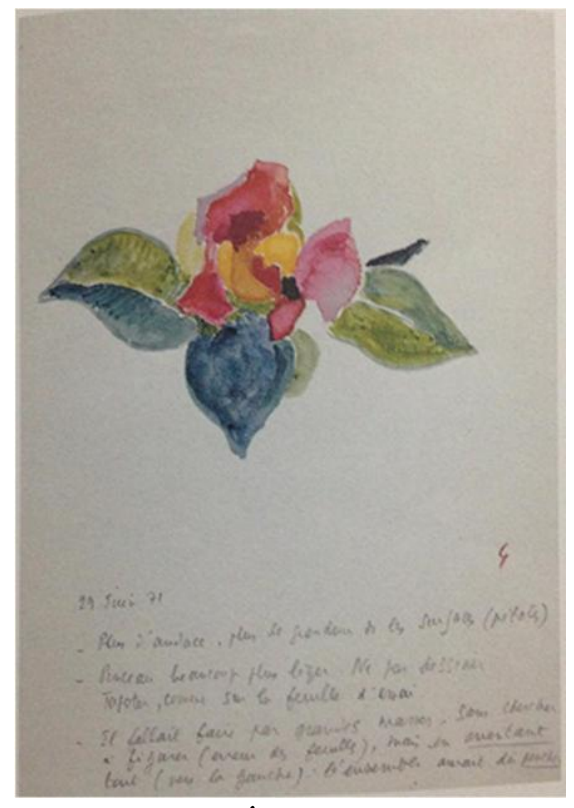

Figura 1

Os leitores entram em contato com a produção gráfica de Barthes pela primeira vez em 1975 com a publicação francesa de Roland Barthes por Roland Barthes, cuja capa é um desenho provavelmente elaborado para tal fim. No livro já podemos ver uma amostra variada do trabalho gráfico de Barthes. Em primeiro lugar, a capa (figura 2) - um de seus desenhos abstratos combinando cores e linhas curvas variadas. Ali podemos encontrar também em um dos desenhos no interior do livro, a figura de um peixe (figura 3) - cuja 
legenda nos indica uma pequena evolução do "fantasma figurativo" presente na flor referida anteriormente - acompanhado de uma assinatura ilegível. Em outro dos desenhos do interior do livro um tachismo feito na folha timbrada da École de Hautes Études. Por último, já no final do livro, duas grafias ilegíveis ou sem significado, acompanhadas das legendas "A grafia por nada..." "ou o significante sem significado". Eis o material gráfico de Roland Barthes por Roland Barthes ligado à prática pictural, ao qual também poderíamos acrescentar, se pensarmos de maneira mais ampla, as fichas de leituras reproduzidas no livro que mostram o vasto prazer que Barthes tinha no uso de instrumentos gráficos.

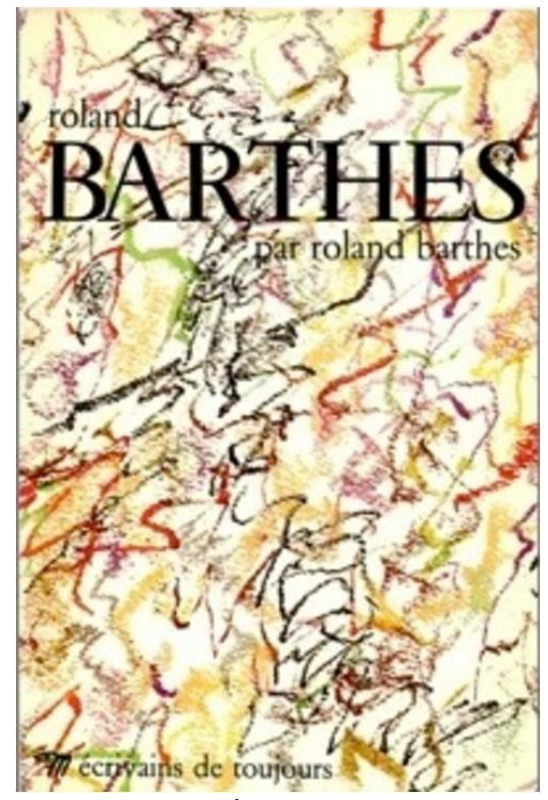

Figura 2

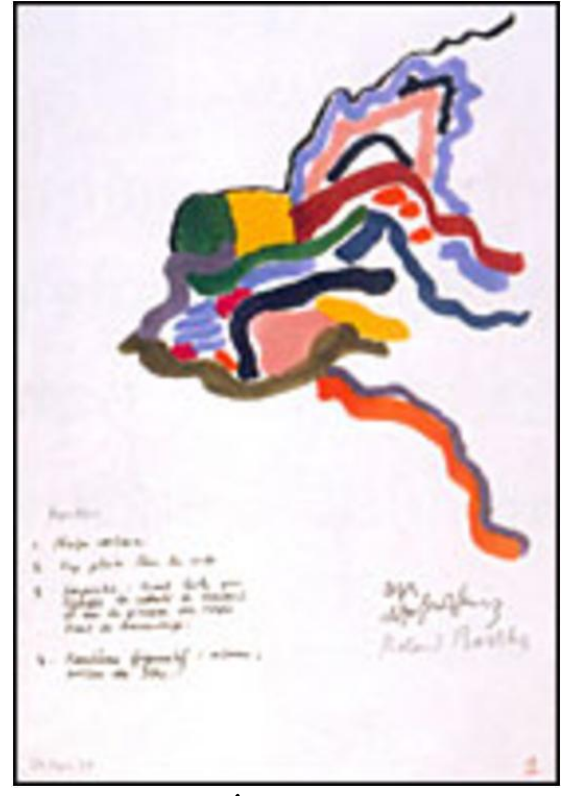

Figura 3

Sua pintura é claramente uma produção que não mobiliza o corpo todo - podemos atestar isso não apenas pela dimensão da tela, pelos traços, mas também pelo seu espaço de trabalho tal como podemos notar em certas fotos e vídeos ${ }^{2}$. Apenas a mão corre com leveza e por vezes tenho a impressão de que essa mão conquista uma liberdade inesperada, talvez uma liberdade que a escrita não proporciona. Ainda assim os traços mantêm uma ligação íntima com a escrita, sem desejar, contudo, significar. Ouso dizer que é uma produção insignificante, se pudermos excluir a carga pejorativa desse termo, mantendo apenas a ideia matriz de não-significação. Ela lembra muitas vezes a aprendizagem dos rabiscos infantis, momento em que a distinção entre a escrita funcional e as técnicas de grafismos ainda são indistintos. A combinação das cores, ao contrário, é sempre extremamente harmoniosa e equilibrada, como que estudada com minúcia antes de aplicada.

As influências são identificáveis e se concentram sobretudo no que podemos chamar vagamente de Expressionismo Abstrato. Podemos identificar alguma semelhança com a produção de Henri Michauxna qual o uso do nanquim sob a superfície branca nos lembra um mesmo tipo de espaçamento, um mesmo tipo de respiro da superfície que há nos desenhos de Barthes (o que talvez venha do investimento dado por ambos tanto à imagem, como à palavra). Também vemos alguma semelhança com André Masson, cujo trabalho vai interessar Barthes sobretudo pelo uso dos ideogramas chineses como dinâmica gráfica,tal como podemos conferir no artigo que Barthes (1990) dedica ao pintor. Barthes está interessado no uso que Masson faz dos ideogramas - principalmente no período de sua obra conhecido como oriental - para experimentar traços, materiais e cores em que a

\footnotetext{
${ }^{2}$ Algumas fotografias do seu escritório podem ser vistas na seção "Iconographie" do site http://rolandbarthes.org. Também podemos conferir tal espaço no início do vídeo promocional de Le plaisir du texte, exibido na televisão francesa em março de 1973, disponível no site do INA: http://www.ina.fr/video/CPF10005880
} 
preocupação de significação seja mantida. Alguma semelhança ainda pode ser estabelecida com as técnicas de Mirtha Dermisache, artista argentina citada por Barthes em "Variations sur l'écriture" (2002d, p. 284)que desenvolve um trabalho caligráfico interessante: escritas indecifráveis, espécies de rasuras ou "desescritas" usando tinta sobre papel, algumas vezes coloridas ou simplesmente feitas em nanquim. As pinturas de Barthes por vezes nos lembram a produção de Jackson Pollock em miniatura, sendo aquele claramente um trabalho que, ao invés de engajar o corpo todo na pintura como em Pollock, mobiliza apenas as mãos. Podemos ainda aproximar as pinturas de Barthes ao trabalho de Bernard Réquichot, principalmente se não levarmos em conta a tridimensionalidade de seus relicários, a variedade de materiais combinados e sua religiosidade, considerando apenas um certo modo de combinar as cores e o emaranhado de traços ${ }^{3}$. Por fim, podemos pensar também em uma relação com Cy Twombly, cujo trabalho muito menos colorido do que o de Barthes e de maior dimensão, desencadeia nele o desejo de reprodução, como atestamos no artigo intitulado "Sagesse de l'art" (2002e, p. 700). Mas, a verdade é que identificar os pontos de contato com a história da arte torna a produção de Barthes extremamente frágil, monótona e desinteressante. Para que a pintura de Barthes tenha algum interesse é preciso associá-la não à história da arte, mas à própria história e à construção do pensamento de Barthes no que concerne à escrita. Acredito que os seus desenhos devam ser estudados, em primeiro lugar, pois são a impressão de um momento presente - daí o primeiro sentido do título desse ensaio: eles são uma espécie de preparo (ou despreparo) para a escrita ou mesmo um o nascimento de um outro modo de escrever.

Pintar é um repouso do império do sentido implicado na escrita e a prática pictural em Barthes é, portanto, indissociável de sua reflexão sobre a escrita e, mais precisamente, de sua reflexão sobre escrita postulada pela literatura contemporânea - essa literatura produzida na década de 1970 na França que se mostra cada vez mais radical, levada até a um ponto da ilegibilidade traduzida verbalmente, como é o caso de Philippe Sollers, Severo Sarduy ou Pierre Guyotat. Tais escritas, em sua ânsia de subversão, parecem propor a destruição da própria escrita, seguindo um topos artístico em voga no momento - e desde então sempre em voga - do fim da arte. Em O Prazer do texto (2013, p. 70-71), Barthes elenca três desdobramentos para esse topos: 1) a possível experimentação de um novo meio (aquele que é escritor poderia se tornar pintor ou cineasta, assim como aquele que pinta ou filma poderia se tornar escritor); 2) a possível reflexão sobre o problema do fim da arte enquanto crítico, coisa que Barthes sempre fez - e desde o momento que passou a praticar a pintura, também procurou refletir sobre a pintura, publicando uma razoável quantidade de textos sobre artes plásticas, fotografia, etc. - ; 3) desistir de ser artista, pondo fim a sua produção. Descartada esta última possibilidade e já tendo estabelecido sua legitimidade enquanto crítico, Barthes descarta a dissimulação do sentido na subversão textual vanguardista de sua época e encontra na pintura, isto é, na experimentação de um novo meio, um tecido possível para a utopia de um texto em que o significante possa imperar sem um significado. Prática que, aliás,de algum modo o libera para que sua própria escrita também se individualize, desembocando na enunciação fragmentada resultante em 0 Prazer do texto ou em Roland Barthes por Roland Barthes. Temos aqui, portanto, um primeiro valor desse novo texto que é a pintura para Barthes: a individuação do sujeito na expressão cumprindo a utopia do texto que a literatura enquanto literatura jamais poderia cumprir.

Na pintura, portanto, não há um texto que comunica. Para usar as palavras do próprio Barthes, na pintura há apenas "um corpo que bate". É certo que a pintura é um gesto, mas a pintura em Barthes contém toda a ambiguidade que esse termo "gesto" pode desencadear. E eis um segundo sentido do que eu chamo aqui pintura presente: seus traços e cores são tanto a impressão de um momento de escrita em que o corpo se faz presente

\footnotetext{
${ }^{3}$ É interessante pensar que Réquichot, assim como Mirtha Dermisache, também desenvolve um trabalho de escrita indecifrável, tendo deixado sua carta de suicídio sob o signo da insignificância, fato que é um tanto marginal em sua obra, mas que certamente retém a atenção de Barthes nesse momento.
} 
através dos gestos daquele que pinta, como um gesto, um endereçamento, um presente, um dom, uma partilha. Como nos conta Renaud Camus: "0 círculo mais íntimo de amigos tomou conhecimento de que Barthes tinha começado a desenhar em 1971. Na ocasião, ele ofereceu uma de suas obras - das primeiríssimas- a Philippe Sollers, como presente de aniversário, durante um jantar pelos seus trinta e cinco anos" (CAMUS, 1995, p. 17-18). É por essa razão que talvez seja ainda mais interessante analisar não as pinturas que compõem o acervo da $\mathrm{BnF}$, material encontrado em grande parte misturado aos manuscritos do autor, mas aquelas que compõem os acervos particulares, aquelas cujo destino foi presentear seus amigos, pois é aí que podemos entrever a característica que talvez seja primordial em sua pintura: Barthes não pinta para ser exposto numa galeria, para se tornar artista; ele pinta para presentear aqueles que ama. Gérard Genette descreve em um breve texto publicado no catálogo da exposição sediada entre 2002 e 2003 no Centre Georges Pompidou o momento em que Barthes presenteia sua mulher com um de seus desenhos:

\begin{abstract}
Ele nos presenteou com uma de suas páginas - com um marcador, parece -, com essa dedicatória que tenho diante dos meus olhos: «Para Babette, esse pequeno "texto". Roland Barthes, 14 set 1972». Set, mesmo sem ser seguido de nenhum ponto não representa o número 7 (julho), mas sim setembro. E como eu tenho a certeza do dia de nossa visita, 20 de abril de 1973, devo inferir que a data escrita não é a da dedicatória, mas a da produção da obra, que o autor dispunha dessa folha há alguns meses, que ele tinha posto a data (e talvez assinado) no dia de sua composição e que ele havia simplesmente escrito a dedicatória propriamente dita em nossa visita, entre o "texto" e a assinatura. Entretanto nada mostra nem na grafia ou na tinta uma distância temporal entre a inscrição da dedicatória, da assinatura ou da data, ainda que a maioria de suas (outras) folhas não fossem de modo algum assinadas (seu nome estando simplesmente no verso) e apenas datadas a lápis; nunca havia um título - nem mesmo "sem título" - o que poderia reivindicar o estatuto de obra. (GENETTE, 2002, p. 99)
\end{abstract}

Sem dar grande importância para a produção em si, sem almejar o estatuto de obra de arte ou ainda sem desejar colocar seus destinatários em dívida com ele, Barthes distribui livremente seus desenhos entre os seus amigos. Essa prática parece ter algo em comum com as cartas e os postais repletos de desenhos e colagens que Michel Butor também distribuía entre os seus amigos ${ }^{3}$. Barthes mesmo conserva algumas dessas cartas, enviadas por Butor na década de 1960, momento em que ele era professor nos Estados Unidos, como nos conta Tiphaine Samoyault em sua biografia (2015, p.393). Esse gesto de partilha é o que podemos ver na coleção de desenhos ofertados a Romaric Sulger Buel, exposta entre agosto e setembro de 1995 no CCBB do Rio de Janeiro, com a curadoria de Silviano Santiago.

Romaric foi aluno de Barthes na École Pratique de Hautes Études e se tornou seu amigo íntimo. Após a morte de Barthes, Romaric conservou 48 desenhos com os quais Barthes the presenteou ao longo dos anos e os trouxe para o Brasil quando se mudou definitivamente para cá ocupando primeiramente o cargo de adido cultural e posteriormente desempenhando um papel importante como produtor na cena cultural brasileira. 0 primeiro desenho de sua coleção é um guache datado de 12 de dezembro de 1971 e, como muitos dos desenhos recebidos até 1975, contém apenas a data e a assinatura a lápis e nenhuma dedicatória. A maior concentração de desenhos de sua coleção é de 1976, ano em que parecem estar bem próximos. Alguns desenhos possuem títulos pessoais como o "Esperando o telefonema" e "Depois do telefonema", ambos de 23 de abril ou ainda títulos mais referenciais como o "Valquíria I" de 7 de agosto e o "Siegfried" de 9 de agosto, referência direta à tetralogia de Wagner encenada por Patrick Chéreau que os dois veem juntos durante o verão.Alguns dos desenhos estão na mesma página ou são marca d'água para pequenos recados legíveis; outros são um exercício de uma escrita ilegível, tal como a de Réquichot ou

\footnotetext{
${ }^{4}$ Alguns dos quais tive o prazer de ver em uma visita à Leyla Perrone-Moisés que me mostrou gentilmente sua coleção privada.
} 
a de Mirtha Dermisache. 0 último desenho de sua coleção, confeccionado em guache, aquarela e caneta hidrográfica, data de 11 de janeiro de 1979 e contém uma referência ao aniversário de Romaric na dedicatória (figura 4).

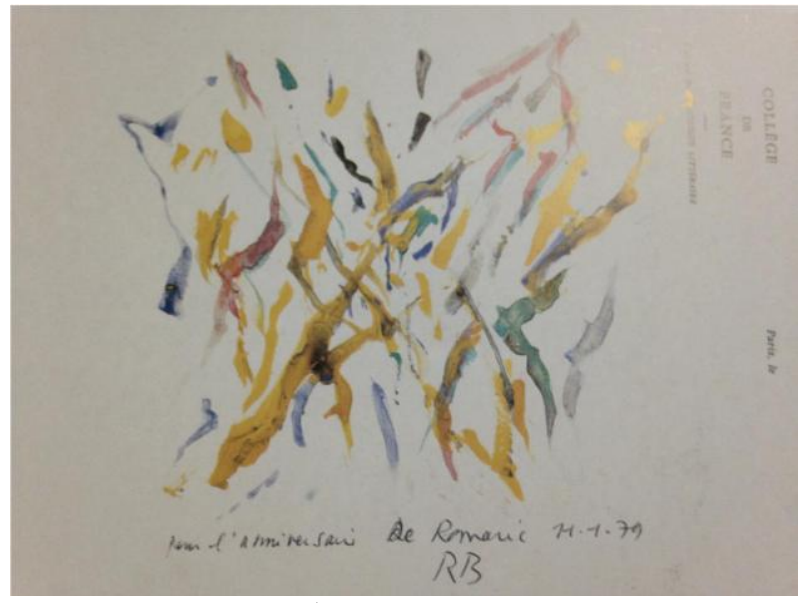

Figura 4

Para concluir, a partir da coleção privada de Romaric - aqui apenas brevemente apresentada - podemos notar que o valor da pintura em Barthes pode muito bem ser atribuído não apenas a uméthos do artista amador ou a um não querer significar: a pintura ganha uma força inédita quando lida sob o signo da anacoluthia, como definido por Barthes em Cerisy (2004, p.444), "o campo raro em que as ideias se penetram de afetividade, em que os amigos, pelo cortejo com que acompanham nossa vida, permitem-nos pensar, escrever, falar". A partir de 1971 a pintura se faz presente na vida de Barthes e na vida dos amigos de Barthes - sem os quais seria impossível pensarmos uma obra tão coletiva como é - Roland Barthes por Roland Barthes. A pintura é um princípio de delicadeza que se estabelece entre eles, de que se extrai do mais banal, do menos prezado, o mais valioso. A pintura presente ofertada por Barthes aos seus amigos é aquele gesto que se distingue do valor obrigatório do trabalho (mesmo o valor estético se faz obrigatório), da polidez ocidental na qual todo presente significa, na qual todo gesto é meticulosamente calculado, pois nessa pintura dois corpos se curvam (figura 5). "Quem saúda quem?" (BARTHES, 2007, 85). Eis a saudação japonesa como descrita em 0 Império dos signos: aquele que oferta se sente tão agraciado quanto aquele que recebe.

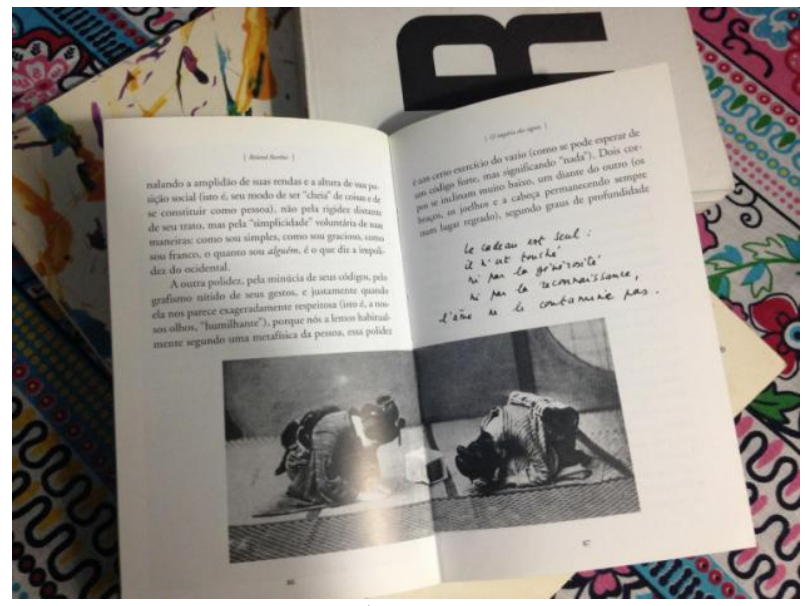

Figura 5 


\section{REFERÊNCIAS}

BARTHES, Roland. "A Imagem" in: 0 rumor da língua. Tradução: Mario Laranjeira. São Paulo: Martins Fontes, 2004.

. O Império dos signos. Tradução: Leyla Perrone-Moisés. São Paulo: Martins Fontes, 2007.

0 prazer do texto. Tradução: Jacó Guinsburg. São Paulo: Perspectiva, 2013.

. Euvres Complètes Vol. IV. Paris: Seuil, 2002d.

. Euvres Complètes Vol. V. Paris: Seuil, 2002e.

- "Semiografia de André Masson", in:Óbvio e obtuso. Ensaios críticos III. Tradução: Léa Novaes. 2 edição. Rio de Janeiro: Nova Fronteira, 1990, pp. 139-141.

CAMUS, Renaud. "Nada a dizer ou a inteligência nua", in: Roland Barthes, artista amador:coleção Romaric Sulger Buel. Rio de Janeiro: CCBB, 1995.

GENETTE, Gérard. "Un jardin sur l'adour", in :R/B: Roland Barthes, Paris: Seuil, 2002.

SAMOYAULT, Tiphaine. Roland Barthes. Paris: Seuil, 2015.

Institut National du Patrimoine. Disponível em

〈http://www.bnf.fr/fr/collections_et_services/anx_tresors_patrimoine/a.c_120605_dessins_bart hes.html . Acesso em 02/06/2015.

INA. Disponível em 〈http://www.ina.fr/video/CPF10005880〉. Acesso em 02/06/2015. 